\title{
Sero Survey of Salmonellosis in Broiler at Sylhet City of Bangladesh
}

\author{
Rubel Miah \\ Department of Physiology \\ Faculty of Veterinary, Animal and Biomedical Sciences. \\ Sylhet Agricultural University, Sylhet-3100 \\ Shameema Khatun \\ Department of Livestock Production and Management. \\ Faculty of Veterinary, Animal and Biomedical Sciences. \\ Sylhet Agricultural University, Sylhet-3100 \\ Md. Nazim Uddin \\ Department of Livestock Production and Management. \\ Faculty of Veterinary, Animal and Biomedical Sciences. \\ Sylhet Agricultural University, Sylhet-3100 \\ Mustasim Famous \\ Department of Livestock Production and Management. \\ Faculty of Veterinary, Animal and Biomedical Sciences. \\ Khulna Agricultural University \\ Obaidul Islam* \\ Department of Livestock Production and Management. \\ Faculty of Veterinary, Animal and Biomedical Sciences. \\ Sylhet Agricultural University, Sylhet-3100
}

\begin{abstract}
The present study was undertaken to know the seroprevalence of Salmonella infection in broiler chickens in the Sylhet area, Northeastern Bangladesh. This investigation was conducted from 10 December 2018 through 20 January 2019. A total of 250 sera samples were collected from five live bird market of the Sylhet metropolitan area and subjected to rapid serum plate agglutination (RSPA) test using commercial salmonella antigen (LilliTest) to detect the presence of antibodies against salmonella infection. The overall prevalence of salmonella infection in the five live bird market visited in this investigation were recorded as $30.6 \%$. The highest prevalence $(46 \%)$ was reported from the samples of Lama bazar. And the lowest prevalence $(20 \%)$ was reported from the samples of Mirabazar. It has been found that Salmonella infections are still significant disease problems in broiler farms in the Sylhet region.
\end{abstract}

Keywords: Prevalence, Mirabajar, Antigen, Agglutination, Infection

DOI: $10.7176 / \mathrm{JNSR} / 12-20-01$

Publication date:October $31^{\text {st }} 2021$

\section{Introduction}

Salmonellosis is an important disease in broiler caused by Salmonella pullorum and Salmonella gallinarum and is usually known as pullorum disease and fowl typhoid, respectively. Pullorum disease occurs in chicks during their first few days of life span and causes severe enteritis and bacteremia (Snoeyenboset al., 1994). Whereas, fowl typhoid is a disease specially occurred in mature chickens and causes either acute enteritis with greenish diarrhea or chronic disease of the genital tract that reduces the production of egg (Prouxet al., 2002). Salmonellosis causes reduction of egg production, increasethe rate of mortality in chickenas resultsignificant economic loss occurs (Khan et al., 1998). Poultry rearing and farming in Bangladesh is expanded day by day where pullorum disease and fowl typhoid have become a widespread problem (Rahman et al., 1979). Salmonella can be diagnosed by observing their different properties such as morphological, cultural, biochemical and serological characteristics of the causal agent. Among serological tests, the rapid plate agglutination (RPA) test is straight forward and used for the detection of Salmonella infection under field condition (Avakian et al.,1988).The application of similiar policy of hygienic measures together with serological testing and slaughter of positive reactors has led to the reduction rate of salmonellosis in many developed countries (Barrow, 1993). In Bangladesh, broiler production is becoming one of the dominant segment of food animal production to meet the demand of the animal protein. Due to the intensive and confined production system, boilers are prone to different 
infectious diseases. In Sylhet region, investigation on poultry diseases like salmonellosis and mycoplasmosis in broiler have received little attention. Thus, the present status of the burden of poultry diseases like Salmonella in Sylhet region is not known. However, Salmonella is one of the primary disease problems in broiler production circuit. Salmonellosis is not only the disease with economic importance but also a significant concern from the public health point of view. Therefore, it is essential to detect salmonellosis in broilers and to know the status of Salmonellosis infection in broiler chickens in the Sylhet region to devise, suggest and practice effective control measures.

Objectives: Main Objectives of the study are:

1.Serological detection of salmonella infection in Broiler.

2.Estimating the burden of salmonella infection in the broiler farms in the Sylhet region

\section{Materials and Methods}

\subsection{Study period}

This investigation was conducted from December 2018 to January 2019 five live bird market (LBM) of the Sylhet metropolitan area -namely,Baluchor Bazar, Shibganj Bazar, Mirabazar,Tilagor Bazar and Lamabazar.

\subsection{Sample size}

We assumed a prevalence of $20 \%$ and $5 \%$ precision, a $95 \%$ confidence level sample size was estimated 246 . The sample size was rounded up to 250 . Thus, the present study was conducted with collecting 250 blood samples from 250 broilers from five different live bird markets of Sylhet city corporation area. The following table shows the size of sample collection from the different markets.

\subsection{Sampling procedure and Preparation of serum}

A total of 250 blood samples were collected from the birds belonging to five LBMs. Blood samples were collected aseptically from each bird during slaughter. Then from each bird two milliliters blood was collectedand placed in a test tube. After that tube with blood was kept in a cool box in a standing position for 6 hoursto clot blood inside the test tube. Serum was harvested by decanting.After clotting, the fluid portion of blood were placed in graduated centrifuge tubes and centrifuged for 30 minitues at $1500 \mathrm{rpm}$. The clear sera was then transferred from the centrifuge tube to sterile vials. Sera samples were stored at $-20^{\circ} \mathrm{C}$ in the laboratory until use for SRPA test .

\subsection{Description of antigens}

The Salmonella antigen used in this study were manufactured by Lillidale Diagnostics, UK for detection of salmonella antibody in the sampled serum. Antigens available in the commercial kit used in this study are the killed and colored Salmonella organisms. Salmonella pullorum antigens from standard (O:1,9,12 ${ }_{1}$ and $\left.12_{3}\right)$ and variant (O:1, 9,12 1 and 122) strains for pullorum disease and fowl typhoid (Prouxet al., 2002).

\subsection{Rapid plate agglutination (SRPA) test}

On the basis of the instructions of the OIE Manual the RPA test was performed (2002). For this test firstly $20 \mu 1$ of antigen and $20 \mu \mathrm{l}$ of Broiler serum were placed side by side with micropipettes on a glass plate. Then antigen and serum sample was stirring with a small tooth pick and mixed thoroughly. Then for avoiding excessive heat from the light source, the glass plate was illuminated from below to simplify observing the reaction. A positive reaction was characterized by the installation of definite clumps within 2 minutes after mixing the test serum with antigen. The clumps usually started appearing and at the periphery of the mixture it became concentrated. The negative reaction was examined by the absence of agglutination reaction. It was done carefully so that the natural granulation of the antigen showed not to be considered as a positive reaction. All SRPA test result was recorded.

\section{Results}

A total of 250 sera samples were collected from different broiler market of Sylhet city during winter (10 December 2018 to 20 January 2019) and tested by serum rapid plate agglutination (SRPA) test to determine the seroprevalence of Salmonella infection. The results of the tests are presented in Table 2.The overall prevalence of Salmonella infection in five markets was30.6\%. The highest prevalence $(46 \%)$ of Salmonella infection was found in the sample of Lamabazar and lowest prevalence $(20 \%)$ of Salmonella infection found in the sample of Mirabazar. The sero prevalence of other three markets was38\% (Baluchor), 26\% (Shibgang), 22\% (Tilagor). 
Table 1: Distribution of samples collected from different market

\begin{tabular}{ccc}
\hline Serial No & Bazar & Number of samples \\
\hline 1 & Baluchor & 50 \\
2 & Shibganj & 50 \\
3 & Mirabazar & 50 \\
4 & Tilagor & 50 \\
5 & Lamabazar & 50 \\
Total & & 250 \\
\hline
\end{tabular}

Table 2: Survey result of Salmonella infection seroprevalence.

\begin{tabular}{cccccc}
\hline Sr.No & Bazar & Sample & Positive & $\begin{array}{c}\text { Prevalence } \\
\text { (positive/ } \\
\text { sample)*100 }\end{array}$ & Confidence interval \\
\hline 1 & Baluchor & 50 & 19 & 38 & $24.65-52.83$ \\
2 & Shibganj & 50 & 13 & 26 & $14.63-40.34$ \\
3 & Mirabazar & 50 & 10 & 20 & $10.03-33.72$ \\
4 & Tilagor & 50 & 11 & 22 & $11.53-35.96$ \\
5 & Lamabazar & 50 & 23 & 46 & $31.81-60.68$ \\
\hline
\end{tabular}

\section{Discussion}

The overall prevalence of Salmonella infection in five markets of Sylhet region was estimated 30.6\%. This seroprevalence indicates higher burden of salmonellosisis in the upper margin of the disease burden. Normally the prevalence of various Salmonella serotypes among live birds ranged from 6\% to 30\% (Liljebjelke et al. 2005; van de Giessen et al. 2006; Gutierrez et al. 2009 and Srinivasan et al. 2014). The prevalence of Salmonellosis found higher in our study than earlier reports ofAlam et al. (2003) and Sarker (2004) who observed 23.8\% and $22.77 \%$ prevalence of Salmonella infection inDinajpur district and Noakhali district of Bangladesh. The difference might be due to the layer, and backyard poultry might have less infection than the broiler chicken. Overall high prevalence indicates the poor hygiene and sanitation standard in broiler farms.In the present study, the SRPA test was performed to determine the seroprevalence of Salmonellae infection in broiler chickens in live bird markets. Avakian et al., (1988) stated that the SRPA test is very simple to perform, highly sensitive and can be used for the detection of Salmonellae infection.However, SRPA test may sometimes show a false positive reaction. To overcome the false positive reactions the test sera were inactivated by heating at 56-degree centigrade for 30 minutes in a hot water bath and retested according to the instruction of OIE Manual (2000) for the confirmation of the results. As farmers in the Sylhet region did not vaccinate chickens against Salmonella in broiler farms, the chance of false positive reaction against induced immunity was very low.

\section{Conclusions}

In the present study, it was revealed that all in all markets broiler birds were positive to Salmonella infection. Further, relatively high prevalence in broiler chickens in local wet markets recapitulate that poultry is undoubtedly a main possible source of salmonellosis and be able to attribute human infection. These results call for the broiler farms, and livebird markets should be periodically checked to know the status of Salmonella infection. This research also highlights the need for accomplishing a stricter hygiene and sanitation standard in broiler farms and local wet markets to minimize the incidence of Salmonella infection.

\section{Authors contribution}

It is clearly stated that all author has contributed significantly to the study.

\section{References}

1. Alam, J., I. Koike, M. Giasuddin and M. Rahman(2003). Seroprevalence of poultry diseases in native chickens in Bangladesh. 9 BSVER Annual thScientificConference,BSVER.PublicationNo. 24, P: 26.

2. Barrow, P. A. (1993). Salmonellacontrol-past, present and future.Avian Pathology, 22:651-669.

3. Bhattacharya, A., \& Majumder, P. (2001). Fowl typhoid outbreak in broiler chick flocks in Tripura and its control. Indian Journal of Animal Science, 71:1034-1035.

4. Gutierrez M, Fanning J, Murphy A, Murray G, Griffin M, Flack A, Leonard N, Egan J.(2009). Salmonella in broiler flocks in the republic of Ireland. Foodborne Pathog. Dis. 6:111-120.

5. Khan, M. A. H. N. A., Bari, A. S. M., Islam, M. R., Das, P. M., \& Ali, M. Y. (1998). Pullorum disease in seminature chicks and its experimental pathology. Bangladesh Veterinary Journal, 32: 124-128.

6. Liljebjelke K.A, Hofacre C.L, Liu T, White D.G, Ayers S, Young S, Maurer J.J.(2005). Vertical and horizontal transmission of Salmonella within integrated broiler production system. Foodborne Pathog. Dis.2: 
90-102.

7. Proux, K., Humbert, F., Jouy, E., Houdayer, C., Lalande, F., Oger, A., \&Salvat, G. (2002). Improvements required for the detection of Salmonella pullorum and gallinarum. Canadian Veterinary Research, 66(3), 151-157.

8. Rahman, M. M., Chowdhury, T. I. M. F., Rahman, M. M., \& Hossain, W. I. M. A. (1979). Surveillance ofSalmonellaand Escherichia organisms in poultry feed. Bangladesh Veterinary Journal, 15:59-62.

9. Snoeyenbos, G. H., Calnek, B. W., Barnes, H. J., Beard, C. W., Reid, W. M., \& Yoder, H. W. Jr. eds (1994). Pullorum disease. In: Diseases of Poultry, Iowa State University Press,USA. pp: 73-86.

10. Minga, U. M., Kikopa, R., Minja, K. S. G. Z., \&Mwasha, J. D. (1987). The prevalence and improved serodiagnosis of fowl typhoid in Tanzania. Proceedings of the $5^{\text {th }}$ Tanzania Veterinary Association Scientific Conference, Tanzania Veterinary Association, pp: 325-338.

11.Mozaffor,K. M., Hossain,Yamato. (2010) Seroprevalence of SalmonellaandMycoplasma gallisepticumInfection in Chickens in Rajshahi and Surrounding Districts of Bangladesh International Journal of Biology,Vol. 2, No. 2; July 2010.

12.Sarker, K.S., (2004). Epidemiological study of Salmonella Diseases and and Mycoplasma infection in selected model breeder poultry farms of Bangladesh. MS Thesis. Submitted to the Dept. of Microbiology and Hygiene, Faculty of Veterinary Science, Bangladesh Agricultural University, Mymensingh, Bangladesh.

13.Srinivasan P, Balasubramaniam G.A, Murthy T.R.G, Saravanan S, Balachandran P(2014). Prevalence and pathology of salmonellosis in commercial layer chicken from Namakkal, India. Pak. Vet. J; 34(3):324-328.

14.Van de Giessen A.W, Bouwknegt M, Dam-Deisz W.D.C, van Pelt W, Wannet W.J, Visser G. (2006). Surveillanceof Salmonella spp. andCampylobacterspp. in poultry production flocks in the Netherlands. Epidemiol. Infect; 134:1266-1275. 